\title{
The impact of electronic payment on electronic shopping decision in Jordan
}

\author{
Khaled Aldiabat \\ Department of Management Information System, College of Business Administration, \\ Ajloun National University, Jordan
}

\begin{tabular}{l} 
Article Info \\
\hline Article history: \\
Received Oct 1, 2018 \\
Revised Dec 10, 2018 \\
Accepted Jan 25, 2019 \\
\hline Keywords: \\
Electronic card type \\
Electronic payment cards \\
Electronic shopping \\
Trust and safety \\
Use and reliability
\end{tabular}

\section{Corresponding Author:}

Khaled Aldiabat,

Department of Management Information System,

College of Business Administration,

Ajloun National University,

PO Box 43, Ajloun, 26810, Jordan.

Email: khaledmis@yahoo.com

\begin{abstract}
Rapid changes in the world of the Internet have led to changes in the electronic markets, especially the speed of information creation compared to normal markets, the reduction of the time between the search and the product, and the ability of the seller and buyer to deal with each other despite the distance between them. The electronic shopping decision depends on the method of payment. This study attempts to measure the effect of e-cards on the decision of e-shopping in Jordan through four aspects, namely: use and reliability, trust and safety, type of e-card and perception. The study reiterated that there is a positive relationship between the use and reliability of electronic cards and the decision of electronic shopping, where the use of electronic cards increases the decision of online shopping, the study also concluded that the type of electronic card and payment method affects the electronic purchase decision (credit card, debit card, prepaid card, cash on delivery).
\end{abstract}

Copyright $(2019$ Institute of Advanced Engineering and Science. All rights reserved.

\section{INTRODUCTION}

Electronic payment cards are the most important electronic payment methods that have developed significantly in the past few years, and the modern alternative to money is widely used in all economically developed societies [1]. As it took the types that fit the requirements of electronic commerce as well as the nature of transactions over the Internet, where it identified different forms based on the function performed as a means of electronic procurement such as (credit card, debit card, prepaid card, cash on delivery) and others [2]. The electronic payment process is the third step of e-commerce after the first one, which is the search for information, the second step is demand, and the third is payment. E-payment is a means of connecting the seller and the buyer, and has many advantages compared to conventional payment, including speed, low cost and continuous development, the most effective means of shopping online, but it faces many risks and obstacles to the consumer or customer [3]. In particular, credit cards, which are a new method of payment rather than traditional methods of cash payment, remain a positive and negative means, as these cards are a means of deferred indebtedness that does not require a certain period of payment [4]. As it is the fastest way to fall into the spiral of debt because of the temptations of banks, especially those with high incomes by raising the ceiling of the card as well as increases the burden and the indebtedness on those who are late in payment on time leading to the burden of benefits. There are a number of issues that affect the electronic payment including: safety, ease of use, type of card, awareness, and increases the risk of electronic payment to the consumer because there is no face-to-face meeting between the seller and the buyer and there is no payment directly [5].

In view of the lack of widespread use of online purchasing in Jordan, online purchasing is widespread throughout the world. The problem of the study is to understand the impact of e-cards on e-shopping decision 
in Jordan. By understanding use and reliability of e-cards, confidence and safety of e-cards, type of e-cards, awareness and perception of e- card.

The reason for choosing this topic is the importance of such studies as a scientific contribution in the field of electronic cards and electronic shopping. The importance of the study is also to know the impact of electronic cards on the decision to purchase through the Internet in Jordan, and to replace electronic cards in the Jordanian society in line with the global trend of the way to consolidate the idea of electronic payment cards as a modern alternative to money in Jordanian society. After studying and researching in relevant studies, it was found that this subject was not discussed by researchers. Most of the previous studies talked about consumer behavior in e-shopping, factors influencing consumer confidence in e-commerce [6], [7], consumer intentions to adopt the idea of paying for Electronic commerce operations [8]-[10]. Direct payment methods and their impact on electronic shopping have not been directly highlighted. The proposed solution to the study problem is to understand the following gaps: the relationship between the use and reliability of electronic payment cards with the decision of electronic shopping in Jordan; secondly, the relationship between trust and safety in electronic payment cards with the decision of electronic shopping in Jordan; Third, the relationship between the type of electronic card and the decision of electronic shopping in Jordan, and finally the relationship between awareness and recognition in electronic payment cards with the decision of electronic shopping in Jordan.

\section{LITERATURE REVIEW}

The fate of electronic payment depends on the development and safety of electronic payment methods. Internet users still lack trust and confidence in this tool, either in terms of providing information about them, or in fear of theft and use of their card numbers by others.

The level of education in any country is an important tool in the dissemination of culture and electronic use. However, the absence of this culture will lead to the emergence of several problems, the most important: the lack of confidence in the payment through electronic means. The electronic payment process has provided easy, fast, secure and relatively low-cost methods for e-business. However, the higher the percentage of electronic payment, the more data, financial and other digital data become susceptible to fraud, and the more electronic payments are developed and the development of similar techniques and methods of fraud. Some methods of payment preferred by some are the method of payment on receipt because of fear of being paid through electronic cards due to fraud or theft, or failure to access the product that was purchased, or the loss of the product, or the arrival of the product to the other side, or the arrival of the product is damaged and all the previous reasons affect the purchase decision of the consumer. All this makes this vital issue to be studied and explained by many studies in a different context at the level of Jordan and the world.

The study of (T. Meyll, et al, 2018) [11] examined whether the use of mobile payment technology is linked to a credit card. Using a sample consisting of more than 25,000 families in the United States, the study found that individuals who use their smartphones to make payments are more likely to display Credit card, also there is a direct relationship between innovative payment methods and increase in spending.

The Alkhlaifat, et al (2017) [12] study dealt with the factors influencing consumer confidence in electronic commerce in Jordan. The study examined the factors that affect the consumer's confidence in ecommerce, supported by evidence taken from the students of the University of Jordan, where the researcher distributed questionnaires to 150 students from the University of Jordan. Based on these surveys, the study concluded that the factors that have a significant impact on consumer confidence in e-commerce are consumer behavior and privacy.

(Halaweh, 2017) [13] referred to the intentions of consumers to adopt the idea of payment of receipt in electronic commerce operations, where the study pointed to the increase in users of payment on receipt in the last few years. The researcher pointed to the lack of research that discussed the process of accepting consumers to the principle of payment for receipt. Accordingly, this study was designed to test and predict the factors that led customers to adopt the payment of receipt in electronic trading operations. The research hypotheses were tested using questionnaires and analyzed using partial low squares (PLS). The results showed that perceived security, privacy, and trust had a key role in raising the use of the payment method.

The study of (Isa et al, 2017) [14] dealt with the process of acceptance of the electronic payment system. The study discussed the reasons for the emergence of the electronic payment system in the government which was mainly attributed to reducing the number of consumers in public queues. The study pointed to the lack of use of this type of systems between the public despite the efforts to encourage them to use these systems. Accordingly, this study was conducted to determine the factors influencing the acceptance of electronic payment systems by consumers. The study showed that the factors influencing were the factor of expectation of performance, factor of expectation of effort, influence factor of social relations, and facilitative constraints. 
The study of (Momani et al, 2017) [15] dealt with the behavior of the electronic consumer in Jordan. The study dealt with the growth rate of electronic purchases in Jordan and their implications for the prosperity of the electronic commerce process in Jordan. The study also confirmed that the analysis of the behavior of individuals gives a deep understanding of their behavior in electronic procurement. This study was designed to investigate six behaviors, namely: the best time to buy, the place, the device used in the purchase, the opinion of the consumer about the offers offered by the websites, the speed of delivery, and the most preferred payment methods of consumers. The study showed that the previous six factors have an effective effect in controlling consumer e-procurement as well as population distribution.

(Sana'a Masuda, 2017) [16] highlighted the role of Jordanian banks in promoting and developing ecommerce and the availability of the elements of electronic banking in Jordanian banks to enable them to play their role in promoting and developing e-commerce, including legal legislation, and community awareness and culture among customers of Jordanian banks, pointing to the lack of the culture of a community and the awareness of banking operations of Jordanian banks customers.

The study of (Yaseen et al,, 2016) [17] discussed the factors that contributed to the spread of electronic commerce in Jordan. The study pointed out that the wide spread of the Internet in developing countries has opened the doors to electronic commerce in a large way as Jordan is part of this system with this huge proliferation of the Internet. Most of these uses of electronic commerce have been embodied through social networking platforms. The study examined the current factors that negatively affect the purchasing process in Jordan.

(Al-Nuemat, 2017) [18] Reviewed the system of Jordanian legislation on credit cards. He pointed out that the use of electronic cards has been widely recognized in recent years due to the spread of banking services in Jordan. He also discussed that legislators in Jordan did not amend the special legislative system of credit cards. As legislation in this regard may affect in many ways, which puts people in confusion and fear of the use of credit cards.

(Lola Hernandez, et al., 2017) [19] Compared cash and Debit Card in terms of their role in controlling the amount of exchange. The reason for this study was the recent global economic problems. The study showed that both cash payment or through debit cards are equally useful to monitor household expenses based on consumers who make purchasing decisions.

(Abu-Shamaa, et al, 2015) [20] Dealt with the factors influencing the intention to buy from electronic stores. The study pointed to the growth of electronic stores in Jordan in exchange for the love of the Jordanian consumer to examine the goods before buying and also the lack of acceptance of many of the electronic payment operations. The study also pointed out that the electronic purchases are directly affected by the technological factor as well as the factor of community culture. This study included the study of these factors and concluded that these factors have an effective impact on the expectation of purchasing intentions of the consumer.

\section{METHODOLOGY OF THE STUDY}

Based on the main objective of the study, the effect of e-cards on the decision of e-shopping in Jordan, the study relied on the descriptive analytical method of completing the study through the following sources of data collection as follows:

a. Secondary data sources: Books, studies, Arab and foreign sources, publications, regulations and instructions issued by the relevant academic and professional bodies in paper and electronic form.

b. Primary data sources: They are collected through a questionnaire consisting of two groups: the first relates to the personal data of the respondents; the second group related to the study questions and the following: the use and reliability, trust and safety, awareness and perception; the questionnaire was summarized and analyzed using the statistical program: Statistical Packages for Social Sciences (SPSS).

\subsection{Community and Sample of the Study}

The study population consists of all the people who carry electronic cards in Jordan. A simple random sample of 263 Arab Bank customers, customers of Banque du Caire Amman and clients of the Housing Bank was selected to answer the questionnaire. When reviewing the data, it was found that there were (13) invalid questionnaire for the statistical analysis. Thus, the study sample consisted of (240) valid questionnaires in the printed questionnaire. Table 1 shows the distribution of the sample according to personal variables. 
Table 1. Distribution of the Sample According to Personal Variables

\begin{tabular}{llll}
\hline Variable & Level & Frequency & Percentage \\
\hline Age & $\begin{array}{l}\text { Less than 25 } \\
\text { years }\end{array}$ & 55 & 22.9 \\
& $\begin{array}{l}\text { From 25 to 40 } \\
\text { years old }\end{array}$ & 157 & 65.4 \\
& $\begin{array}{l}\text { From 41-55 } \\
\text { years old }\end{array}$ & 23 & 9.6 \\
& Over 55 years & 5 & 2.1 \\
& Total & 240 & 100.0 \\
Gender & Male & 136 & 56.7 \\
& Female & 104 & 43.3 \\
Education & Total & 240 & 100.0 \\
level & General & 27 & 11.3 \\
& Secondary & & \\
& School & 18 & 7.5 \\
& Diploma & 148 & 61.7 \\
& BA & 148 & 18.8 \\
& M.A. & 45 & 0.8 \\
& Ph.D. & 2 & 100.0 \\
Nature of & Total & 240 & 37.5 \\
work & Governmental & 90 & \\
& institution & & \\
& Private & 113 & 47.1 \\
& institution & & \\
& free business & 22 & 9.2 \\
& Retired & 15 & 6.3 \\
& Total & 240 & 100.0 \\
\hline & & & \\
\hline
\end{tabular}

The highest percentage of the distribution of the study population according to the age variable was (65.4\%) for the age group (25-40 years), the lowest percentage was $(2.1 \%)$ for the age group (over 55 years) whereas the percentage of females was (43.3\%). The highest percentage of the distribution of the sample was according to the educational level variable was (61.7\%) for the educational level (bachelor), while the lowest percentage was $(0.8 \%)$ for the educational level $(\mathrm{PhD})$. The highest percentage of the sample was distributed according to the nature of work was $(47.1 \%)$ for the nature of work (private establishment), while the lowest percentage was $(6.3 \%)$ for the nature of work (retired).

\section{RESULTS AND DISCUSSION}

This chapter presents the results of the study which aims to identify electronic payment systems and their impact on the purchasing process in Jordan. This will be done by answering the study questions. First: correlation coefficients between the variables of the study:

Table 2. The Correlation Coefficients between the Study Variables were Extracted

\begin{tabular}{|c|c|c|c|c|c|c|}
\hline \multicolumn{2}{|c|}{ variables of the study } & $\begin{array}{l}\text { Use and } \\
\text { reliability }\end{array}$ & $\begin{array}{l}\text { confidence } \\
\text { and safety }\end{array}$ & $\begin{array}{l}\text { Awareness } \\
\text { and } \\
\text { perception }\end{array}$ & $\begin{array}{c}\text { Type of } \\
\text { electronic } \\
\text { card }\end{array}$ & $\begin{array}{c}\text { Decision } \\
\text { of } \\
\text { e-shopping } \\
\end{array}$ \\
\hline $\begin{array}{l}\text { Use and } \\
\text { reliability }\end{array}$ & $\begin{array}{l}\text { Pearson } \\
\text { Correlation } \\
\text { Sig. (2-tailed) }\end{array}$ & & & & & \\
\hline $\begin{array}{l}\text { confidence } \\
\text { and safety }\end{array}$ & $\begin{array}{l}\text { Pearson } \\
\text { Correlation } \\
\text { Sig. (2-tailed) }\end{array}$ & $\begin{array}{l}.581 \\
.000\end{array}$ & & & & \\
\hline $\begin{array}{l}\text { Awareness } \\
\text { and } \\
\text { perception }\end{array}$ & $\begin{array}{l}\text { Pearson } \\
\text { Correlation } \\
\text { Sig. (2-tailed) }\end{array}$ & $\begin{array}{l}.428 \\
.000\end{array}$ & $\begin{array}{l}.271^{* *} \\
.000\end{array}$ & & & \\
\hline $\begin{array}{l}\text { Type of } \\
\text { electronic } \\
\text { card }\end{array}$ & $\begin{array}{l}\text { Pearson } \\
\text { Correlation } \\
\text { Sig. (2-tailed) }\end{array}$ & .286 & $\begin{array}{l}.315 \\
.000\end{array}$ & $\begin{array}{l}.300 \\
.000\end{array}$ & & \\
\hline $\begin{array}{l}\text { E - } \\
\text { shopping } \\
\text { decision }\end{array}$ & $\begin{array}{l}\text { Pearson } \\
\text { Correlation } \\
\text { Sig. (2-tailed) }\end{array}$ & .512 & .425 & $\begin{array}{l}.481 \\
.000 \\
\end{array}$ & $\begin{array}{l}.294 \\
.000 \\
\end{array}$ & \\
\hline
\end{tabular}


The previous table shows that all correlation coefficients between the study variables were statistically significant. Second: Results of applying the simple linear regression test

1. The study shows the application of simple linear regression test to study the effect of the use and reliability of electronic cards on the decision of electronic shopping in Jordan.

Table 3. The Results of Applying the Analysis of Mono-variance to Study the Impact of the Use and Reliability of Electronic Cards on the Decision of Electronic Shopping in Jordan

\begin{tabular}{ccccccc}
\hline Independent variable & $\begin{array}{c}\text { Value of } \\
(\beta)\end{array}$ & $\begin{array}{c}\text { Value of } \\
(\mathrm{t})\end{array}$ & $\mathrm{R}$ & $\mathrm{R}^{2}$ & $\begin{array}{c}\text { Value of } \\
(\mathrm{F})\end{array}$ & $\mathrm{Sig}$ \\
\hline Use and reliability for e-cards & 0.51 & 9.20 & 0.51 & 0.26 & 84.57 & 0.00 \\
\hline
\end{tabular}

As shown in Table 3, there is a medium relationship between the use and reliability of electronic cards with the decision of electronic shopping in Jordan, where the value of this relationship (0.51), and through the value of the coefficient $\mathrm{R}$ (square) (26\%) of the variance in the electronic shopping decision variable, since the value of $(F)$ was (84.57) and the statistical significance level was $(0.000)$ which means the significance of the regression at the level of significance $(\alpha \leq 0.05)$ and the value of $(\mathrm{t})$ was $(9.20)$, with the statistical significance (0.000), which means that the coefficient is also significant at the $(\alpha \leq 0.05)$. It it possible to say that there is a statistically significant relationship at the level of significance $(\alpha \leq 0.05)$ between the use and reliability of electronic cards with electronic shopping in Jordan's decision. The results of the study agreed with (T. Meyll, et al, 2018) [11], which showed that there is a direct correlation between use e-card payment and online shopping decision.

2. The study shows the application of simple linear regression test to study the effect of confidence and safety of electronic cards on the decision of electronic shopping in Jordan.

Table 4. The Results of the Application of the Analysis of Mono-variance to Study the Impact of Confidence and Safety of Electronic Cards on the Decision of Electronic Shopping in Jordan

\begin{tabular}{crrrrrr}
\hline Independent Variable & Value $(\beta)$ & Value(t) & $\mathrm{R}$ & $\mathrm{R}^{2}$ & Value (f) & Sig \\
\hline $\begin{array}{c}\text { confidence and safety of e- } \\
\text { cards }\end{array}$ & 0.43 & 7.24 & 0.43 & 0.18 & 52.37 & 0.00 \\
\hline
\end{tabular}

As shown in Table 4, there is an intermediate relationship between confidence and safety of electronic cards with the decision of electronic shopping in Jordan, where the value of this relationship was (0.43), and through the value of the coefficient ( $\mathrm{R}$ square), the variance in the electronic shopping decision variable. Since the value of $\mathrm{F}$ is equal to (52.37) and its statistical significance was (0.000), meaning the significance of the regression at the level of significance $(\alpha \leq 0.05)$. The value of $(\mathrm{t})$ is equal to $(7.24)$, and the statistical significance level was (0.000), which means the significance of the coefficient also at the level of significance $(\alpha \leq 0.05)$, it can be said that there is a statistically significant correlation at the level of significance $(\alpha \leq 0.05)$ between trust and safety of electronic cards with the decision of electronic shopping in Jordan. The results of the study agreed with (Halaweh, 2017) [13], which showed a steady increase in pay-per-receipt users showed that perceived security, privacy and trust had a major role in adopting the idea of payment for receipt.

3. The study shows the application of the simple linear regression test to study the effect of the type of electronic card on the decision of electronic shopping in Jordan.

Table 5. The Results of the Application of the Analysis of the Single Variance to Study the Impact of the Type of Electronic Card on the Decision of Electronic Shopping in Jordan

\begin{tabular}{lllllll}
\hline Independent Variable & Value $(\beta)$ & Value $(\mathrm{t})$ & $\mathrm{R}$ & $\mathrm{R}^{2}$ & Value $(\mathrm{f})$ & $\mathrm{Sig}$ \\
\hline Type of e-cards & 0.48 & 8.46 & 0.48 & 0.23 & 71.58 & 0.00 \\
\hline
\end{tabular}

As shown in Table 5, there is a medium relationship between the type of electronic card and the decision of electronic shopping in Jordan, where the value of this relationship was (0.48), By using the value of R square, the use and reliability of electronic cards accounted for $26 \%$ of the variance in the electronic shopping decision variable. Since the value of $\mathrm{F}$ is equal to 84.57 and the statistical significance is $(0.000)$ The significance of the regression at the significance level $(\alpha \leq 0.05)$, the value of $(t)$ is $(9.20)$, and the statistical significance level was $(0.000)$ This means the significance of the coefficient also at the level of significance 
$(\alpha \leq 0.05)$, it can be said that there is a statistically significant relation at the level of significance $(\alpha \leq 0.05)$ between the use and reliability of electronic cards with the decision of electronic shopping in Jordan. The study shows the application of simple linear regression test to study the impact of awareness and perception of the electronic card on the decision of electronic shopping in Jordan. The results of the study not agreed with (Lola Hernandez, et al., 2017) [19], which the study showed that either cash payment or through debit cards are equally useful to monitor household expenses based on consumers who make purchasing decisions.

Table 6. The Results of the Application of the Analysis of the Single Variance to Study the Impact of Awareness and Perception of the Electronic Card on the Decision of Electronic Shopping in Jordan

\begin{tabular}{lllllll}
\hline Independent Variable & Value $(\beta)$ & Value $(\mathrm{t})$ & $\mathrm{R}$ & $\mathrm{R}^{2}$ & Value $(\mathrm{f})$ & Sig \\
\hline $\begin{array}{l}\text { awareness and perception of e- } \\
\text { card }\end{array}$ & 0.29 & 4.75 & 0.29 & 0.09 & 22.52 & 0.00 \\
\hline
\end{tabular}

As shown in Table 6, there is a medium relationship between the awareness and perception of e- card with the decision of electronic shopping in Jordan, where the value of this relationship (0.29), and through the value of the coefficient of identification ( $\mathrm{R}$ square), it shows that awareness and perception of the e- card explains (29\%) of the variance in the electronic shopping decision variable. Since the value of $F$ is 22.52 with a statistical significance 0.000 , meaning the significance of the regression at $\alpha(0.05)$. The value of $(\mathrm{t})$ is equal to (4.75), with a statistical significance (0.000), which means that the coefficient is also significant at the level of significance $(\alpha \leq 0.05)$, it can be said that there was a statistically significant relationship at the level of significance $(\alpha \leq 0.05)$ between awareness and perception of the electronic card with the decision of electronic shopping in Jordan. The results of this study were agreed with the study of (Sana'a Masuda, 2017) [16], which showed the lack of a culture of community and awareness of banking operations among customers of Jordanian banks, which affect the promotion and development of e-commerce.

\section{CONCLUSION}

The study aimed at identifying the impact of e-cards payment on the decision of e-shopping in Jordan. The study concluded that there is a positive relationship between the use and reliability of electronic cards and the decision of e-shopping. The use of electronic cards increases the decision to shop online. The study also concluded that trust and safety affect the decision of e- shopping, and therefore the websites must ensure the confidentiality and security of electronic cards during the purchase process of unauthorized access. The majority of consumers in Jordan resort to payment on receipt because of their fear of being paid via electronic cards due to fraud or theft, and the use of electronic cards, credit card, debit card, prepaid card and cash on delivery, or the arrival of the product on the other hand, or the arrival of the product is damaged and all the previous reasons affect the purchase decision of the consumer. The Jordanian consumer does not prefer buying through credit cards because of the temptations of banks, especially those with high incomes, by raising the card's ceiling to them, which results in increased interest for those who are in arrears. The study concluded that there is a relationship between awareness and perception and the decision of e-shopping, awareness and perception and the community culture of electronic banking operations plays an important role in the spread and development. The level and quality of education in any country is an important means of spreading culture and electronic use.

\section{REFERENCES}

[1] L. P. Chin, et al., " Consumers' Intention to Use a Single Platform E- Payment System: A Study Among Malaysian Internet and Mobile Banking Users," Journal of Internet Banking and Commerce, Vol. 20, pp. 1-13, Apr 2015.

[2] Y. S. Aldeen, et al., "New Trends in Internet of Things, Applications, Challenges, and Solutions," TELKOMNIKA Telecommunication, Computing, Electronics and Control, vol. 16, pp. 1114-1119, Jun 2018.

[3] L. Fernandes, "Fraud in Electronic Payment Transactions: Threats and Countermeasures," Asia Pacific Journal of Marketing \& Management Review, vol. 2 (3), pp. 23-33, Mar 2013.

[4] T. C. Okeke, et al., "Service Quality Dimensions and Customer Satisfaction with Online Services of Nigerian Banks," Journal of Internet Banking and Commerce, vol. 20, pp. 1-26, Dec 2015.

[5] L. Zheng, et al., "Chinese consumer perceived risk and risk relievers in e-shopping for clothing," Journal of Electronic Commerce Research, vol. 13, pp. 255-275, Aug 2012.

[6] I. E. Mani, "A Study on the Impact of Demonetization on Electronic Payment System," Indian Journal of Applied Research, vol. 7, pp. 486-488, Jul 2017.

[7] S. Sfenrianto, at el., "E-commerce recommender for usage bandwidth hotel," Indonesian Journal of Electrical Engineering and Computer Science, vol. 9, pp. 227-233, Jan 2018. 
[8] S. Ghosh, at el., " Swing-Pay: One Card Meets All User Payment and Identity Needs: A Digital Card Module using NFC and Biometric Authentication for Peer-to-Peer Payment," IEEE Consumer Electronics Magazine, vol. 6, pp. 82-93, Jan 2017

[9] M. Bourlakis, at el., "E-consumer behavior: Past, present and future trajectories of an evolving retail revolution," International Journal of E-Business Research, vol. 4, pp. 64-67, Jan 2008.

[10] S. Sato, et al., "A Daily-level Purchasing Model at an E-commerce Site," International Journal of Electrical and Computer Engineering (IJECE), vol. 2, pp. 931-839, Dec 2012.

[11] T. Meyll, et al., "Tapping and waving to debt: Mobile payments and credit card behavior," Finance Research Letters, vol.25, Jun 2018.

[12] B. I. Alkhlaifat, et al., "Factors Affecting Consumers' Trust Towards E-Commerce: Evidence from Jordanian Students' Perspective," European Journal of Business and Management, vol. 9, pp. 54-59, 2017.

[13] M. Halaweh, "Intention to Adopt the Cash on Delivery (COD) Payment Model for E-commerce Transactions: An Empirical Study," from book Computer Information Systems and Industrial Management: 16th IFIP TC8 International Conference, CISIM 2017, Bialystok, Poland, June 16-18, 2017, Proceedings pp.628-637.

[14] M. A. Isa, et al., "The Consumer Acceptance Towards Electronic Payment System," Global Conference on Business and Economics Research (GCBER) 2017, 14-15 Aug 2017 Universiti Putra Malaysia, Malaysia, Proceedings pp. 58-65.

[15] A. M. Momani, et al., "Investigating the Behavioral Preferences of the Jordanian Online Shoppers," International Journal of Contemporary Computer Research, vol. 1, pp.13-20, Jul 2017.

[16] M. Masuda, "The Availability of the Elements of Electronic Banking in Jordanian Banks to Promote and Develop Electronic Commerce", Al-Quds Open University Journal for Research and Studies, vol. 2, pp. 349-388, Jun 2011.

[17] H. Yaseen, at el., "Facilitating E-Commerce in Jordan: A Qualitative Analysis", International Journal of Digital Society (IJDS), vol. 7, pp. 1206-1213, Dec 2016.

[18] A. A. Al-Nuemat, "The Legal System for Credit Cards in Jordan," Scientific Research an Academic Publisher, vol. 8, pp. 171-191, Jun 2017.

[19] L. Hernandez, at el., "Cash versus debit card: the role of budget control," Journal of Consumer Affairs, vol. 51, pp. 91-112. Spring 2017.

[20] R. Abu-Shamaa, at el., "Factors influencing the intention to buy from online stores: An empirical study in Jordan," 2015 IEEE 8th GCC Conference \& Exhibition, 1-4 Feb 2015, Muscat, Oman, Proceedings pp. 1-6.

\section{BIOGRAPHIES OF AUTHORS}

Khaled Aldiabat, Department of Management Information System, Ajloun National University,
khaledmis@ yahoo.com, Jordan.
Researcher in the fields of e-government, e-commerce, e-banking, knowledge management, cloud
computing and e-business management

